pragMATIZES - Revista Latino Americana de Estudos em Cultura

Ensaio 


\section{Veredas abertas da América Latina}

\section{Antonio Albino Canelas Rubim'}




\section{Veredas abertas da América Latina}

\author{
O Para Eduardo Galeano \\ e Gonzalo Carambula \\ As formas desaparecem, \\ as palavras ficam, \\ para significar o impossível. \\ Augusto Roa Bastos
}

\section{Introdução}

O escritor gaúcho Luiz Antonio de Assis Brasil no romance histórico Figura na Sombra traça a errática vida do naturalista Aimé Bonpland, companheiro de Alexander von Humboldt na sua viagem de cinco anos pelas Américas. Contemporâneo da Revolução Francesa, botânico de Josefina e Napoleão, amigo de Simon Bolívar e prisioneiro doditador paraguaio Doutor Francia, Amado Bonpland, tomado pela natureza, passa por uma mutação identitária, deixa a Europa para viver e morrer na América do Sul.

\section{O escritor paraguaio Augusto} Roa Bastos em seu livro Eu o supremo desvela a figura enigmática e real de José Gaspar Francia, el supremo, ditador e leitor dos iluministas. No livro reencontramos Amado Bonpland, prisioneiro do supremo durante anos. Ele tece a história do Paraguai em um texto singular que Angel Rama disse inclassificável, devido a seu transito sem fronteiras por variados gêneros: romance, história, biografia, ensaio sociológi$\mathrm{co}$, dentre outros.

A literatura, assim como o cinema e a música, no século $X X$, articularam, expressaram e deram vida à América Latina. Propiciaram diálogos interculturais. O realismo fantástico de Gabriel Garcia Marquez e o real maravilhoso de Alejo Carpentier conversam sobre sua realidade mágica. Os filmes de Glauber Rocha e Fernando Solanas conformaram imagens duras e poéticas da América Latina. A música de Violeta Parra, Mercedes Soza, Astor Piazolla, Caetano Veloso e Gilberto Gil nos permitiramauscultar sotaques, sons e sonoridades latino-americanas. Cito só alguns dos criadores culturais deste complexo, diverso e rico espaço cultural, ainda tenazmente em construção (GARRETÓN, 2003)

Ditaduras e neoliberalismos agrediram e deixaram sequelas profundas neste espaço cultural. Monopólios midiáticos de produção e difusão culturais continuam invadindo, quase sempre com violência, corações e mentes. As culturas latino-americanas resistem e se afirmam, apesar da violência, dos monopólios e das condições desiguais e injustas, das visões colonizadoras e colonizadas. Seus movimentos, por vezes ambíguos e muitas vezes criativos, alternam fluxos e refluxos históricos, tensos, de assimilação e contraponto com as concepções de mundo hegemônicas no mundo capitalista.

No recente horizonte do século $\mathrm{XXI}$, as mutações sociais, econômicas, políticas e culturais acontecidas, em especial nos países latino-americanos pós-neoliberais, abriram novas veredas para superar tal supremacia e possibilitar novos diálogos interculturais. A emergência vigorosa de movimentos político-culturais possibilitou novos horizontes possíveis para a cultura. Aautoafirmação de novos segmentos, antes excluídos em múltiplas dimensões - sociais, econômicas, políticas e culturais - estão se traduzindo eminovadores processos culturais. Este texto trata de um deles: a cultura viva na América Latina. 


\section{Cultura Viva}

Reconhecer, apoiar e potencializar o que já existe culturalmente. Princípio simples e surpreendente para políticas culturais, em especial, para aquelas voltadas para setores sociais e culturais antes excluídos de qualquer relação cultural com o estado nacional. Faz mais de 10 anos que o Programa Cultura Vivacomeçou a acontecer no Brasil. O ano de nascimento foi 2004. No ano anterior, a confluência de constelações, com Lula presidente e Gilberto Gil ministro, começou a abrir novas veredas para a cultura viva do povo brasileiro. O programa pretende autonomia, protagonismo, empoderamento e trabalho em redede agentes e comunidades culturais. Inaugurado o Programa Cultura Viva, ele cresceu em números, orçamento e repercussão. Tentacular, ele tomou o Brasil. O Ministério da Cultura antes adstrito a poucos territórios do país e concentrado em Brasília, Rio de Janeiro e São Paulo, se esparramou pelo Brasil e dialogou com regiões nunca dantes visitadas. Brotaram pontos de cultura, pontões de cultura, pontinhos, pontos de leitura, pontos de memória, economia viva e outras ações inscritas no programa, em desenvolvimento desigual e nem sempre combinado.

O conceito ampliado de cultura, constantemente anunciado e reafirmado por Gilberto Gil (2003), e aspolíticas de promoção e preservação da diversidade cultural assumidas pelo Ministério da Cultura, possibilitaram e deram força ao programa. Ele criou uma base social nova para um ministério criado em 1985, mas verdadeiramente reinventado a partir de 2003. Desde então o Ministério da Cultura não se relaciona só com artes e patrimônio, áreas tradicionais de sua atuação histórica, mas com a sociedade brasileira em sua complexidade, com agentes e comunidades culturais nunca antes acionadas e reconhecidas pelo estado nacional. Não parece casual que o programa tenha se instalado formalmente na Secretaria da Cidadania Cultural. Passo relevante para a ampliação do programa aconteceu em 2007, quando estados e depois municípios se integram na gestão do Programa Cultura Viva, ainda que nem sempre de maneira compartilhada e explicitamente federativa (ROCHA, 2011).

A expansão do programa gerou dificuldades não enfrentadas até 2010, ano final do governo Lula. Ainda que elas possam ter alguma relação com aadministração do programa, não parece ser este $\mathrm{o} x$ da questão. Entretanto, a partir de 2011, nas gestões das ministras Ana de Hollanda e depois Marta Suplicy e da agora Secretaria da Cidadania e Diversidade Cultural, dirigida por Márcia Rosenberg, o problemafoi tratado, acima de tudo, como questão gerencial, comoproblema de gestão. Em consequência, o programa ficou quase paralisado até 2014. A incompreensão envolveu a não percepção do papel do Programa Cultura Viva no alargamentoda base social e de atuação do ministério, como ficou evidente na gestão Ana de Hollanda. A indiferença da gestão seguinte, de Marta Suplicy, não alterou o paradeiro instalado. Em suma, nestes anos os desafios e inovações do programa foram ignorados, sem mais.

O Programa Cultura Viva, ao fazer interagir o estado nacional com atores, comunidades e modalidades marginalizados culturalmente, expôs de modo contundente o caráter excludente e denunciou a inadequação existente no Brasil entre estado e sociedade. O estado existente não se voltava para tais setores sociais, antes atendia apenas demandas dos segmentos dominantes. Transformar este escandaloso sintoma em questão de ajustes administrativos e burocráticos 
deprimiuo potencial de rebeldia contra o estado elitista. Os pontos de cultura exigem, pelo contrário, refundar o estado, em uma perspectiva radicalmente democrática e republicana. Ser coerente com o programa implica em não esquecer seu traço inovador, sempre incômodo, nem olvidar seu caráter potencialmente subversivo. A utopia de outro estado e de outro mundo, inscritos no programa, deve ser assumida como possível em toda sua plenitude (RUBIM, 2011).

A gestão quase dedicada aos aspectos burocráticos e gerenciaisdebilitou o programa equase o destituiu de seu papelquestionador frente ao caráter de classe e ao elitismo do estado brasileiro. Sua incorporação como política ter sido mantida, ainda que debilitada, decorreu de suas virtudes: de suas visibilidades, nacional e internacional, bem como de certo empoderamento conquistado por seus ativistas. Eles impediram um destino mais drástico. Foram eles, em conjunto com forças político-culturais aliadas, que, mesmo neste panorama sóbrio, viabilizaram a aprovação da Lei Cultura Viva. A lei $n^{\circ} 13.018$ de 22 de julho de 2014, regulamentada em 08 de abril de 2015, instituiu o Programa Nacional Cultura Viva, que assim passou a ser uma política de estado, ainda que o estado não tenha sido adequadamente democratizado, com a superação dos impasses do programa.

Dentre as dezenas de estudos já existentes sobre o programa, três deles, realizados pelo Instituto de Pesquisa Econômica Aplicada (IPEA) do Governo Federal, traçam um amplo e crítico panorama do programa. Conforme os estudos do IPEA existiam no Brasil mais de três mil pontos de cultura, cujas ações atingiamoito milhões de pessoas de modo esporádico, 900 mil de maneira regular e envolviam 33 mil trabalhadores, metade deles remunerados (BARBOSA; ARAÚ-
JO, 2010; BARBOSA; CALABRE, 2011; BARBOSA; LABREA, 2014). O retorno em 2015, de Juca Ferreira, ex-secretário executivo de Gilberto Gil e ex-ministro entre 2008 e 2010, ao Ministério da Cultura pretendia reverter esta difícil situação, visando atingir a meta prevista no Plano Nacional de Cultura: 15 mil pontos de cultura em 2020 (MINISTÉRIO DA CULTURA DO BRASIL, 2012).

\section{Cultura Viva Comunitária}

Em contraste com a paralisia brasileira, floresceu na América Latina a partir de 2010 um movimento que foidenominado de Cultura Viva Comunitária. Já no ano de 2009, no III Congresso Ibero-Americano de Cultura, promovido pela Secretaria Geral Ibero-Americana (SEGIB), em São Paulo, aconteceram diálogos. Mas o marco inicial do processoocorreu em Medellín, de 13 a 16 de outubro de 2010, no Encuentro de Redes Latinoamérica Plataforma Puente - 100 Organizaciones Socioculturales. Mais 100 entidades da sociedade civil e instituições públicas de cultura reivindicaram $1 \%$ dos orçamentos nacionais para a cultura e $0,1 \%$ para uma cultura viva sem fronteiras. Neste mesmo ano, realizou-se uma marcha em Buenos $\mathrm{Ai}$ res e a entrega na Casa Rosada de proposta de lei Cultura Viva. No ano seguinte, também na Argentina, aconteceu o IV Congresso Ibero-Americano de Cultura. Ele reforçou a ideia dos percentuais, definiu as experiências da cultura viva comunitária e criticou a ausência de políticas culturais especificamente voltadas para ela. Neste momento, a Argentina já possuía centenas de pontos e circuitos (pontões) de cultura.

No Fórum da Cultura Viva Comunitária, realizado em setembro de 2012, também na cidade de Medellín, o Programa Nacional de Cultura Comunitária 
da Colômbia delimitou seu campo como conjunto de processos, experiências e expressões culturais que surgem nas comunidades, a partir da cotidianidade e da vivência de seus territórios, promovidas por entidades enraizadas em seus próprios territórios (PLATAFORMA PUENTE, 2012). Características elencadas da Cultura Viva Comunitária: pertencimento comunitário, familiar e cotidiano; ação cultural desenvolvida no espaço público, ruas e praças; vinculação com economia social e solidária; protagonismo das mulheres, jovens e adolescentes; ações voltadas para a cultura de paz; trabaIho em rede; democracia deliberativa, participativa e comunitária; cuidado do meio-ambiente e dos bens comuns; predisposição para a mestiçagem estética e cultural; vocação para a transformação territorial através de movimentos sociais, intervenção política e de cidadania (BALÁN, 2012).

Todo este vertiginoso processo deságua, em maio de 2013, no I Congresso Latino-Americano de Cultura Viva Comunitária, realizado em La Paz, com mais de 1.300 pessoas de 17 países, abrangendo territórios que se estendem desde o México até o Chile. O VI Congresso Ibero-Americano de Cultura, organizado pela SEGIB, em maio de 2014,assume como tema Cultura Viva Comunitária. Nele se discute a criação do Fundo Ibercultura Viva para financiar grupos comunitários, a exemplo de programas já existentes: Ibermuseus, Ibermídia, Ibermúsica etc. Em 29 de agosto de 2014, a Rede Chilena de Cultura Viva Comunitária realizou seu I Encuentro Pluricultural Cultura Viva Comunitaria. O II acontece em 30 de agosto de 2015. Em novembro de 2014, em Córdoba, ocorre o I Congresso Nacional Cultura Viva na Argentina. Representantes da Argentina, Bolívia, Brasil, Chile, Colômbia, Costa Rica, El Salvador, Equador, Guatemala, Peru e Uruguai, que fazem parte do Conselho Latino-Americano da Cultura Viva Comunitária, se reúnem em São Paulo de 03 a 7 de dezembro de 2014 para discutir a situação nos países e a Semana de Cultura Viva Comunitária.

O movimento hoje alcança quase todos os países latino-americanos: Argentina, Belize, Bolívia, Brasil, Chile, Colômbia, Costa Rica, El Salvador, Equador, Guatemala, Honduras, Nicarágua, Panamá, Peru, Uruguai e Venezuela.As exceções na América do Sul parecem ser Guiana, Suriname e Guiana Francesa.Além de países, cidades se tornam agentes do programa. Medellín foi a primeira cidade latino-americana a ter uma lei de Cultura Viva Comunitária, aprovada em 2011. De 25 a 28 de outubro de 2015realiza-se em El Salvador o II Congresso Latino-Americano de Cultura Viva Comunitária.

\section{Formulações e reformulações}

A expansão do Programa Cultura Viva para a América Latina não significou apenas a assimilação mimética de uma experiência vitoriosa no Brasil, ainda que entravada e tendo que superar os percalços políticos anotados. Bem distinta da mera cópia, tal ampliação se realizou através de intenso diálogo intercultural com condições e concepções de cada um destes locais assinalados. Desta maneira, o Programa Cultura Viva Comunitária, em processo de rica construção, resultou de um complexo processo de assimilações, trocas e transmutações, que incorporou experiências nacionais e locais diferenciadas, e, simultaneamente, desenvolveuvisões comuns e compartilhadas. Análises mais detalhadas dos variados processos em andamento nos diversos países latino-americanos irão demonstrar este caráter, ao mesmo tempo, diverso e comum. De imediato, o per- 
fil comunitário foi densamente afirmado e reforçado. Por certo, ele está presente no experimento brasileiro, mas não com tal nitidez, identidade e potência. O recurso ao termo "comunitária" na titulação do programa torna-se emblemático desta nova circunstância.

Outra diferença, observada por Luana Vilutis (2015), diz respeito à presença das culturas digitais no programa. No caso brasileiro, ela aparece como expressiva, devido a sua relevância para a construção de redes e ao obrigatório kit tecnológico instalado em cada ponto de cultura. Na Cultura Viva Comunitária, com algumas exceções nacionais, as culturas digitais apresentam-se mais como um desafio a ser alcançado que um conjunto de experiências efetivamente realizadas, mesmo que sua relevância seja devidamente reconhecida.

A análise de Luana Vilutis assinala outra dimensão fundamental das reformulações acontecidas na Cultura Viva Comunitária: a influência que as culturas originárias passam a ter na cosmovisão do programa, em especial aquelas que podem ser traduzidas como "bem viver", tais como sumakkawsay (Equador) e suma qamaña (Bolívia). Cabe lembrar que o "bem viver" (sumakkawsay) foi incorporado mesmo como elemento da nova constituição do Equador de 2008, não sem disputa e tensões sobre o sentido desta incorporação como demonstram recentes conflitos no Equador (CASTRO, 2015 e CASTRO; PABÓN, 2015).

A incorporação da cosmovisão de povos originárias traz ou explicita um conjunto relevante de concepções que passam a marcar o ideário do programa e implicam em sua reformulação, sem abandonar suas formulações originárias advindas da experiência brasileira. Novas camadas de sentido são acionadas para dar mais consistência e singularidade ao programa. Os princípiosda complementariedade e da relacionalidade passam a ser ainda mais assumidos como valores. O equilíbrio e a satisfação das necessidades, individuais e coletivas, devem se realizar através da compreensão que existe uma complementariedade indissociável entre sociedade e natureza. Da mesma maneira que a vida humana implica sempre em coexistência e convivência em relação aos outros. A comunidade assume expressivo lugar na vida social. Ela emerge como o modo básico de organização da sociedade. Ela se conforma através do acionamento de consensos, diálogos e assembleias. Neste novo horizonte, complementariedade, relacionalidade e harmonia apresentam-se como vitais para configurar o bem viver.

A convivência cidadã em harmonia com natureza e com comunidade se contrapõe às visões e modos de vida trazidos e impostos pelos colonizadores. A destruição e o silenciamento impingidos pela colonização ocidental não teve potência suficiente para destituir estes povos e comunidades de sua cosmovisão, mesmo que a tenha afetado e rivalizado. A persistência, apesar de tudo, destas concepções de mundo possibilita um bom alicerce para a luta pela descolonização do saber naquelas regiões e registros onde a colonização se impôs com mais força. A reafirmação e realização do bem viver implicam, por conseguinte, na busca continuada de descolonização do saber, na disputa em torno de modos de ver e viver o mundo.

Ainda que o tema do desenvolvimento esteja distante dos imaginários dos povos originários e seja, por conseguinte, um componente nascido e trazido pela visão de mundo ocidental, cabe assinalar que a inscrição da América Latina neste contexto cultural contemporâneo impõe o tema do desenvolvimento como complexa 
questão a ser enfrentada por estes países, como assunto inexorável a ser discutido e enfrentado. As relações entre a cosmovisão do bem viver e o desenvolvimento não parecem simples e tranquilas. Elas não podem ser esquecidas e desconsideradas, mas configuram-se sempre como complexas, necessárias e tensas.

\section{Observações finais}

Obrigatório agora uma "viagem à semente", para lembrar o interessante conto de Alejo Carpentier. Cabe revisitar os anos 60 e 70 do século XX, quando a América Latina se integrou e recriou nas maravilhosas obras de muitos de seus criadores culturais. Seus intelectuais, artistas e pensadores, umbilicalmente associados aos movimentos político-culturais e ao seu tempo/espaço, teceram inventivamente a América Latina. No século XXI, esta tessitura parece vir também ou principalmente de outro horizonte cultural: dos ativistas e comunidades político-culturais colocados em movimento, em especial, pelas recentes mudanças políticas e culturais em andamento na América Latina, com destaque para os países pós-neoliberais, que terminaram contaminando a região. Diferente da criativa circunstância anterior, hoje os agentes destas manifestações culturais locais, mestiçagens de reafirmações do local em um ambiente intensamente global, parecem ser setores populares, com seus ativistas e suas comunidades culturais, que conquistaram mais efetivamente sua cidadania cultural e passaram a exercer seus direitos culturais. Tal mutação deve ser encarada em toda sua novidade e potência nas dimensões políticas e culturais. Ela resulta e expressa a nova América Latina, reinventada no século XXI.

A afirmação do local, de suas tradições, modos de vida e cosmovisões, não significa a busca nostálgica de um mundo quase perdido, mas novas possibilidades de diálogos entre tradição e modernidade, mesmo que isto não se faça sem arestas e fricções. A reafirmação das tradições opera em um ambiente globalizado e aciona recursos próprios desta sociedade rede, para lembrar Manoel Castells. Pesquisa realizada nos anos de 2004 e 2005, inserida nas Cátedras de Integración do Convenio Andrés Bello, sob o título de Políticas e redes de intercambio e cooperação em cultura no âmbito ibero-americano, constatou a existência naqueles anos de poucas redes culturais na região, mas detectou também uma expansão crescente das redes entre 1998 e 2004: de zero para 16 redes, em aumento constante (RUBIM; RUBIM; VIEIRA, 2006). O panorama atual, sem dúvida, aponta para uma proliferação de redes e de redes que congregam redes. Esta constelação de redes possibilita reavivar o velho sonho da América Latina integrada, mas como o reconhecimento, na contemporaneidade, de sua diversidade cultural, de sua mestiça interculturalidade e da urgência de mais e melhores diálogos interculturais. A Cultura Viva e a Cultura Viva Comunitária fazem parte deste complexo, longo e rico processo de transformação social.

\section{Bibliografia}

ASSIS BRASIL, Luiz Antonio de. Figura na sombra. Porto Alegre: L\&PM, 2012.

BALÁN, Eduardo. Cultura, descolonización y buen vivir. In: ROLDÁN, Jairo Adolfo Castrillón (org.) Memorias del Foro Nacional de Cultura Viva Comunitaria. Medellín: Corporación Cultural Canchimalos, 2013. Disponível em http://www.semiosfera.org.co/ foromedellin.pdf. Acesso em 21 agosto de 2015.

BARBOSA, Frederico; ARAÚJO, Herton (orgs.). Cultura Viva. Avaliação do Programa Arte, Educação e Cidadania. Brasília: Instituto de Pesquisa Econômica Aplicada, 2010. 
BARBOSA, Frederico; CALABRE, Lia (orgs.). Pontos de Cultura: Olhares sobre o Programa Cultura Viva. Brasília: Instituto de Pesquisa Econômica Aplicada, 2011.

BARBOSA, Frederico; LABREA, Valéria (orgs.). Linhas gerais de um planejamento participativo para o Programa Cultura Viva. Brasília: Instituto de Pesquisa Econômica Aplicada, 2014.

BASTOS, Augusto Roa. Eu o supremo. Rio de Janeiro: Paz e Terra, 1977.

CARPENTIER, Alejo. Viagem à semente. In: BUENO, Salvador (org.) Contos cubanos do século XX. Curitiba: Criar Edições, 1986. p.79-90.

CASTRO, Luísa de.; PABÓN, Santiago. Dilemas plurinacionais de um projeto em disputa. Brasil de Fato. São Paulo, 20 a 26 de agosto de 2015. p.13.

CASTRO, Luísa de. Protestos e mobilização nacional agitam o Equador. Brasil de Fato. São Paulo, 20 a 26 de agosto de 2015. p.13.

GARRETÓN, Manuel Antonio (org.). El espacio cultural latinoamericano. Bases para una política cultural de integración. Bogotá: Convênio Andrés Bello; México: / Fondo de Cultura Económica, 2003.

GILBERTO, Gil. Discursos do Ministro da Cultura Gilberto Gil. Brasília: Ministério da Cultura, 2003.

HOUTARD, François. Dos bens comuns ao bem comum da humanidade. Bruxelas: Fundação Rosa Luxemburgo, 2011.

HOUTARD, François. El concepto de sumakkawski (buen vivir) y su correspondencia en el bien común de la humanidad. 2011. Disponível em: http:www//alainet.org/es/active/47004. Acesso em 21 agosto 2015.

MINISTÉRIO DA CULTURA DO BRASIL. As metas do Plano Nacional de Cultura. Brasília: Ministério da Cultura, 2012.

MINISTÉRIO DA CULTURA DO BRASIL. Seminário Internacional do Programa Cultura Viva. Novos mapas conceituais. Brasília: Ministério da Cultura, 2009.

PlATAFORMA PUENTE. Programa Nacional Cultura Viva Comunitária. Disponível em www. culturavivacomunitaria.org/cv. Acesso em 21 agosto 2015.
ROCHA, Sophia. Programa Cultura Viva e seu processo de estadualização na Bahia. Salvador, Universidade Federal da Bahia, 2011. Dissertação de mestrado em Cultura e Sociedade.

RUBIM, Antonio Albino Canelas. As políticas culturais e o governo Lula. São Paulo: Editorada Fundação Perseu Abramo, 2011.

RUBIM, Antonio Albino Canelas. Programa Cultura Viva. Projetos Pontos de Cultura. In: MINISTÉRIO DA CULTURA DO BRASIL. Seminário Internacional do Programa Cultura Viva. Novos mapas conceituais. Brasília: Ministério da Cultura, 2009. p.21-22.

RUBIM, Antonio Albino Canelas; RUBIM, Iuri; VIEIRA, Mariella Pitombo. Actores sociales, redes y políticas culturales. In: CONVENIO ANDRES BELLO. Cátedras de integración Convenio Andrés Bello. Bogotá: Convênio Andrés Bello, 2006. p.13-64.

TURINO, Célio. Cultura a unir povos. Revista Observatório Itaú Cultural. São Paulo, n. 18, julho/dezembro de 2015. p. 66-75.

TURINO, Célio. Pontos de Cultura. O Brasil de baixo para cima. São Paulo: Anita Garibaldi, 2009.

VILUTIS, Luana. Presenças e ausências da economia solidária nas políticas culturais. Salvador, Universidade Federal da Bahia, 2015. Tese de Doutorado em Cultura e Sociedade.

I Antonio Albino Canelas Rubim. Pesquisador do CNPq e do Centro de Estudos Multidisciplinares em Cultura (CULT). Professor do Programa Multidisciplinar de Pós-Graduação em Cultura e Sociedade (Pós-Cultura) da Universidade Federal da Bahia (UFBA), Brasil. Contato: rubim@ufba.br 